\title{
Etapas finais do conflito de delimitação da fronteira marítima Chile-Peru perante a Corte Internacional de Justiça
}

\author{
Gustavo Luiz von Bahten 1
}

\section{RESUMO}

Durante o ano de 2013, a Corte Internacional de Justiça emitirá sentença a respeito da controvérsia entre as repúblicas do Peru e do Chile, buscando a delimitação da fronteira marítima entre os dois países. O artigo busca apresentar os principais pontos desta controvérsia, ressaltando os acontecimentos mais recentes neste julgamento.

Palavras-chave: Chile; Peru; Corte Internacional de Justiça.

Em 14 de dezembro de 2012, no Palácio da Paz, em Haia, sede da Corte Internacional de Justiça, finalizaram-se os debates orais relativos à controvérsia iniciada no início de 2008, visando à delimitação da fronteira marítima entre as repúblicas do Peru e do Chile, buscando resolver definitivamente uma controvérsia histórica sobre a soberania de uma região de forte importância econômica, porque rica em recursos pesqueiros, ocupando $38324 \mathrm{~km}^{2}$ do Oceano Pacífico.

Parte significativa da área objeto da controvérsia encontra-se atualmente sob a soberania do Estado chileno, uma vez que foi perdida pelo Peru após a guerra do Pacífico, em 1883. Outra porção da área objeto da demanda peruana não se encontra sob o domínio de país algum, uma vez que, para os chilenos, seria alto mar.

O Peru busca na CIJ a delimitação do limite marítimo entre os países, alegando que tais fronteiras jamais foram estabelecidas, e que devem ser fixadas com base no direito consuetudinário. Afirma que desde os anos de 1980 tentou, por 2 diversas

\footnotetext{
${ }^{1}$ Advogado, graduado em Direito pela UFPR, mestre pela Universidade de Heidelberg (Alemanha) e PhD pela Universidade de Milão (Itália). Contato: gbahten@vonbahten.com.br
} 
ocasiões, uma solução pacífica para essa questão, mas que Santiago sempre recusou qualquer tentativa de negociação.

A controvérsia ganhou novos contornos em 1997, quando o Chile, ao ratificar a Convenção de Montego Bay - Convenção Internacional de Direito Marítimo -, depositou, perante as Nações Unidas, suas cartas náuticas, indicando suas fronteiras marítimas, entre elas o limite com o Peru, com base no paralelo $18^{\circ} 21^{\prime}$ 00" S. 0 Peru, então enviou um comunicado às Nações Unidas, formalizando seu não reconhecimento aos limites apontados pelos chilenos.

Nos primeiros anos deste novo século, Lima buscou mais uma vez iniciar negociações bilaterais com o Chile a fim de delimitar os ditos limites marítimos, mas Santiago deu a questão por encerrada, uma vez que, de acordo com os chilenos, os limites já se encontram estabelecidos desde os anos de 1950.

Em 2005, o Congresso peruano aprovou a lei 28.621, estabelecendo as fronteiras marítimas do país - Lei de Linhas de Base do Domínio Marítimo, tomando por base o critério da equidistância (bissetriz), e não mais o do paralelo reconhecido pelo Chile. Assim sendo, o Peru abarcava uma área considerada por Santiago como de soberania chilena. Tal lei foi objeto de severas críticas por partes da República do Chile, que, no ano seguinte, por sua vez, promulga a lei 20.175, criando a $15^{\text {a }}$ região (Arica e Parinacota), estabelecendo os limites do norte do Chile com o Peru. Desta feita, foi a diplomacia peruana que acusou os chilenos de violarem a soberania peruana. Tal lei foi, todavia, considerada inconstitucional pela Corte Constitucional chilena, e os limites entre os dois países permaneceram incertos.

Em 2007, o governo chileno enviou às Nações Unidas um protesto contra a lei peruana de limites, sendo tal objeção respondida por Lima com a tese de que a delimitação marítima com o Chile fora feita por Santiago de forma unilateral. Como se pode perceber, a controvérsia relativa aos limites marítimos entre Peru e Chile chegava a seu ápice.

Em 16 de janeiro de 2008, a República do Peru apresentou formalmente o caso perante a Corte Internacional de Justiça, invocando o artigo XXXI do Pacto de Bogotá de 
1948, que Peru e Chile firmaram sem reservas. Em março de 2008, fixou-se o prazo para os memoriais (20/03/2009) e contramemoriais (09/03/2010) dos países.

A tese sustentada por Lima afirma que a fronteira marítima Peru-Chile jamais fora delimitada, e que esta deveria sê-lo a partir de um ponto apresentado pelos peruanos e denominado de "Ponto Concordia" - definido como a interseção entre a linha de baixa-mar de um arco de dez quilômetros de raio, que tem como centro a primeira ponte sobre o Rio Lluta na ferrovia Arica-La paz - equidistante das linhas de base de ambos os países, ate o limite de 200 milhas náuticas entre os países. Tal limite encontraria fulcro no tratado de 3 de junho de 1929 que estabeleceu as fronteiras de Tacna (Peru) e Arica (Chile). Além disso, para os peruanos, seu país possui soberania exclusiva até a distância de 200 milhas náuticas da linha de base peruana sobre uma área hoje considerada como alto-mar pelos chilenos.

Em 2009, os chilenos apresentaram sua resposta, pedindo que a demanda peruana fosse rejeitada, declarando-se que as fronteiras marítimas entre os países já se encontram regularmente estabelecidas por acordos bilaterais anteriores, especialmente pela Declaração de Santiago de 1952 e pelo Convênio sobre a Região Especial Fronteiriça Marítima de 1954, e que, portanto, o Peru não possui razão para rediscutir temas já consolidados. Tais acordos teriam sido confirmados por atas bilaterais de 1968 e 1969. Para os peruanos, por outro lado, tais tratados são apenas relativos a temas pesqueiros, e não devem ser aplicados na definição das fronteiras entre os países. De acordo com Santiago, a fronteira marítima entre os países é limitada pelo paralelo de latitude $18^{\circ} 21^{\prime}$ 00" S, e, assim sendo, o Peru não possui nenhum direito sobre as águas ao Sul deste paralelo.

Em 27 de abril de 2010, a corte autorizou uma réplica peruana (com prazo ate 09/11/2010) e uma tréplica chilena (até 11/07/2011), seguidas da fase de debates orais, ocorridos em Haia entre os dias 3 e 14 de dezembro de 2012. A resolução do conflito interessa a diversos países da região, sendo que Colômbia, Equador e Bolívia já requisitaram expressamente cópias dos procedimentos junto à CIJ.

Agora se iniciará a fase de deliberações dos magistrados, nas quais os membros da Corte - de maneira privada - discutirão o caso em tela. Inicialmente haverá uma discussão preliminar, durante a qual se fixarão os pontos controvertidos. Cada juiz, Conjuntura Global, Curitiba, Vol. 2, n.1, jan./mar., 2013, p. 3-7. 
então, elaborará um documento com suas opiniões sobre o caso, que será distribuído aos demais juízes. Em seguida, haverá nova deliberação, e a definição de um comitê que redigirá a sentença, sujeita a emendas. Neste ínterim, os demais juízes poderão elaborar declarações ou votos em separado. Somente ao final deste procedimento aprovar-se-á um texto final da decisão, o qual será publicado.

Não será a primeira vez que a Corte Internacional de Justiça pronunciar-se-á sobre este tema, vide os casos Nicarágua v. Colômbia (pendente), Romênia v. Ucrânia (2009), Nicarágua v. Honduras (2007), Camarões v. Nigéria (2002), Catar v. Bahrain (2001), Guiné-Bissau v. Senegal (1995), Dinamarca v. Noruega (1993) e El Salvador v. Honduras (1992), mas certamente será um dos casos mais emblemáticos da história da corte. A decisão da CIJ dirimirá uma controvérsia historicamente relevante para toda a região, resolvendo definitivamente a questão de limites entre Peru e Chile, em disputa desde a Guerra do Pacífico, na segunda metade do século XIX.

\section{Referências Bibliográficas}

AHUMADA, Javiera Araya. RIVAS PARDO, Pablo. La cuestión marítima: Chile y Perú en La Haya. In: Working paper 37 - Programa Defensa y Seguridad. Centro Argentino de Estudios Internacionales. Buenos Aires: CAEI, 2010.

ARIAS-SCHREIBER, Alfonso. Delimitação da Fronteira Marítima entre o Peru e Chile. In:

Revista peruana de Direito Internacional, Lima, v. 51, n.117, 2001. Janeiro/junho 2001. Disponível em: www.contexto.org/pdfs/delimitacion_frontera.pdf Consultado em 07 de fevereiro de 2013.

BIBLIOTECA DEL CONGRESO NACIONAL DE CHILE. Tratados internacionais Chile-Peru (1929, 1952,1954, 1968 e 1969). Disponível em: http://www.bcn.cl/lc/tinterna/define?titulo=\&pais=Per\%C3\%BA\&periodo=0\&Sub mit=\&aux=1 - Consultado em 08 de fevereiro de 2013.

CARRASCO, Jorge. Posición chilena en La Haya: Un Apoyo Informado. In: Apuntes Interncaionales, de 09 de novembro de 2012. Disponível em: 
http://www.apuntesinternacionales.cl/posicion-chilena-en-la-haya-un-apoyoinformado/ - Consultado em 08 de fevereiro de 2013.

CASTRONOVO, Valério. Piazze e caserme: I dilemmi dell'America Latina dal Novecento a oggi. Roma-Bari: Laterza \&Figli Spa, 2007.

COLLIER, John. LOWE, Vaughan. The settlement of disputes in international law: institutions and procedures. New York: Oxford University Press, 1999.

CONGRESO NACIONAL DEL PERÚ. Lei 28.621 - Lei de linha de base do domínio marítimo do Peru. Disponível em:

http://www.congreso.gob.pe/ntley/imagenes/Leyes/28621.pdf - Consultado em 08 de fevereiro de 2013.

CORTE INTERNACIONAL DE JUSTIÇA. Contentious cases: Maritime Dispute (Peru v. Chile). Disponível em:

http://www.icj-cij.org/docket/index.php?p1=3\&p2=3\&code=pc\&case=137\&k=88

- Consultado em 15 de fevereiro de 2013.

EL MERCURIO. Especiales: Relaciones Chile-Perú. Disponível em: http://www.emol.com/especiales/infografias/conflictochile_peru/index.htm, Consultado em 15 de fevereiro de 2013.

MOGNI NOVOA, Alessandro Miguel. Controvérsia sobre delimitação marítima entre o Peru e o Chile: expansionismo peruano ou pleno uso do Direito Internacional? Rio de Janeiro: $\quad$ ESG, 2011. Disponível em http://www.esg.br/uploads/2012/03/MOGNINAlessandro.pdf - Consultado em 07 de fevereiro de 2013. 